\title{
Biosensors for the detection of pesticides
}

\author{
J.-L. Marty, B. Leca and T. Noguer \\ Centre de Phytopharmacie, Université de Perpignan, 52 avenue de Villeneuve, 66860 Perpignan Cedex, France
}

\begin{abstract}
This review presents the last advances in the field of biosensors for pesticide detection. The main categories of reported sensors are presented according to the immobilized biological sensing element: immunosensors, enzyme sensors and "whole cell" sensors. The potential of each type of sensor in environmental monitoring is discussed and the advantages and drawbacks of the described devices are highlighted.
\end{abstract}

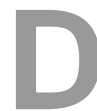
uring the past 50 years, pesticides have been used in increasing amounts throughout the world. Until recently, the identification and quantitation of pesticide residues in water and other sources have been limited to the traditional chromatographic and spectroscopic methods. Although they are very sensitive, these sophisticated techniques are time consuming and require highly trained personnel and expensive apparatus. Furthermore, these methods are unsuitable for real-time, in-situ or on-line monitoring of pollutants. A considerable attention is now being given to the development of biosensors that can provide continuous, in-situ and rapid measurement of various compounds. A biosensor can be defined as a device resulting from the association between a sensitive biological element and a transducer, which converts the biological signal into a measurable physical signal [1].

Various types of biosensors have been developed in the field of environmental monitoring. Depending on the nature of the biological sensing element, they can be divided into immunosensors, enzyme sensors, organite-based sensors and whole cell sensors. The presently available tranducers can be broadly divided into electrochemical, optical, mass sensitive and thermal devices.

The main sensors developed for environmental monitoring are based on immunological reaction, enzyme inhibition or inhibition of metabolic reactions (for a review, see [2]).

\section{Immunosensors}

Since their appearance, immunoassays (IA) have spread rapidly in clinical analysis [3-5]. However, food science and environmental analysis have realized only recently that this methodology was a valuable new quantitative technique and a good alternative to conventional procedures [6,7]. All immunoassays are based on the highly selective and sensitive antibody $(\mathrm{AB})$-antigen $(\mathrm{AG})$ reaction. They all use labels to detect the immunological reaction, these labels can be enzymes (Enzyme Immunoassay, EIA), radioactive (Radioimmunoassay, RIA) or fluorescent chemicals
(Fluorescence Immunoassay, FIIA). Enzyme immunoassays (EIA) use enzyme labels to amplify and visualize primary antigen-antibody binding reaction and is the most widely used immunoassay technology today. They avoid the unpleasant use of radioisotopes employed in radioimmunoassay formats (RIA). Enzyme labels are easy to handle, inexpensive and are used to convert a colorless substrate into a colored product providing sensitivity and simplicity. Among the enzyme immunoassays (EIA), those based on heterogeneous conditions are most commonly employed and are refered to enzyme-linked immunosorbent assays (ELISAs) [8]. For ELISAs, either AB or AG are immobilized on a solid phase to facilitate the separation of free and bound fractions. ELISAs can be grouped in three categories: direct competitive ELISA, indirect competitive ELISA and sandwich ELISA.

The possibilities of immunoassays as detection methods in water quality control, i.e. for screening as well as for monitoring, have been reviewed in many papers [9-11]. Among the commercial immunoassay kits for pesticide analysis, major suppliers are Ohmicron (Newton, USA) for RaPID Assay kits (J.T. Baker), Res-I-Mune (Millipore Corp., Bedford, USA) for EnviroGard kits and Quantix (Cinnaminson, USA).

Unlike conventional immunoassays, an immunosensor should be capable to detect the analyte continuously and selectively, and to give a response in real time. In general, the direct detection of the binding of immunoreagents does not provide enough sensitivity. A label allowing a more sensitive detection of the immunological reaction is thus necessary. These labels can be either an enzyme, a fluorescent chemical or an electrochemically active substance. Enzymatic labels used in immunosensor devices are usually oxidoreductases such as peroxidase (HRP) or hydrolytic enzymes such as alkaline phosphatase. Immunosensors can be divided into four classes, depending on the transducer employed: piezoelectric [12-14], optical [15-17], electrochemical $[18,19]$, or thermometric. The immobilized sensing element can be either an antibody (AB) or an antigen (AG) wich can be chemically modified (hapten). In the first case, the binding of the antigen on the immobilized antibody is directly measured. In the second case, the method is based on the competition between immobilized AG, the analyte $(\mathrm{AG})$, and a fixed amount of $\mathrm{AB}$.

\section{Piezoelectric immunosensors}

Piezoelectrics are materials (usually quartz crystals) that may be brought into resonance by the application of an external alternating electric field. The frequency of the resulting oscillation is determined by the mass of the crystal. In immunosensors, the surface of the piezoelectric is usually coated with an antibody or an antigen (hapten) and the mass variation induced by the antigen-antibody binding is correlated to the concentration of the antigen. 
Piezoelectric immunosensors have been described for the detection of pesticides such as the herbicide atrazine $[13,14]$ and the insecticide parathion [12]. For instance, Guilbault et al. [13] have developed a direct detection device using protein A to orientate the antibodies on the crystal adequately. Using this system, they achieved the detection of $0.03 \mathrm{ppb}$ atrazine. Two commercial devices exist to prepare piezoelectric immunosensors: the PZ 106 Immunobiosensor System (Universal Sensors Inc., New Orleans, USA) and model QCA 917 (EG\&G, Princeton Applied Research, New Jersey, USA).

\section{Optical immunosensors}

Optical immunosensors are based on the measure of the absorption or emission of light by the immunoreactants. Fibre optic sensors usually consist of an optic fibre strand having an appropriate sensing layer on the distal tip of the fibre. Light travels along the fibre by total internal reflexion. The interactions between light and the reactant can be measured as changes in absorbance, luminescence, polarization or refractive index. The main optical immunosensors developed for environmental monitoring are based on surface plasmon resonance (SPR) devices. An SPR immunosensor is a classical SPR device modified with an immobilized antibody layer. When the antigen binds to the immobilized antibody, the SPR device detects minute changes in the refractive index as a shift in the angle of total absorption of light incident on a metal layer carrying the antibodies. Optical immunosensors can also be based on evanescent wave (EW) transducers. An evanescent wave is produced in external media by an electromagnetic field associated by light guided in a waveguide by total internal reflexion. The main immunosensors based on this principle used labelled molecules that are able to re-emit the absorbed evanescent photons at a longer wavelenght as fluorescence, this phenomena is called total internal reflection fluorescence (TIRF). Minunni and Mascini [20] used the commercial SPR apparatus BIAcore ${ }^{\mathrm{TM}}$ from Pharmacia (Uppsala, Sweden) to detect the herbicide atrazine. In this case, an atrazine conjugate was immobilized on the sensor surface and the carrier stream contained a known amount of free antibody and the herbicide analyte. Such a non-labelled competitive device allowed to achieve a detection limit of $0.05 \mathrm{ppb}$. This example, together with those reported in table I, shows that immunosensors are able to give fast and sensitive measurements.

\section{Electrochemical immunosensors}

Detection by electrochemical sensors is inexpensive and allows to achieve very low detection limits when coupled to chemical amplification systems such as enzymes. Electrochemical measurements fall into two broad classes: potentiometric and amperometric.

\section{Potentiometric immunosensors}

An antibody is a protein whose electric charge is affected by the binding of an antigen. Potentiometric immunosensors are based on the measure of a change in potential induced by the binding of free $A G$ or $A B$ on its specific immobilized partner. Direct detection often leads to small changes in potential, so that a poor sensitivity and low precision is obtained. Furthermore, such systems suffer from non spe-
Table I. Optical immunosensors involving competitive reactions.

\begin{tabular}{lcccc}
\hline $\begin{array}{l}\text { Immobilized } \\
\text { reagent }\end{array}$ & $\begin{array}{c}\text { Detected } \\
\text { compound }\end{array}$ & Labelled reactive & $\begin{array}{c}\text { Detection } \\
\text { limit }(p p b)\end{array}$ & Ref. \\
\hline Hapten & Terbutryn & No & 3.6 & {$[17]$} \\
& Atrazine & No & 3.2 & \\
Hapten & Atrazine & 0.05 & {$[20]$} \\
Hapten & Parathion & Fluorescein Anti IgG & 0.3 & {$[15]$} \\
Antibody & Imazethapyr & Fluorescein & 0.3 & {$[16]$} \\
Antibody & Polychloro- & Hapten & & {$[21]$} \\
& phenols & Hapten & 10 & {$[22]$} \\
& \multicolumn{4}{c}{} \\
\hline
\end{tabular}

cific binding reactions. In order to increase the sensitivity of these sensors, enzyme labels are often linked to immunoreactants. In such systems, the transducer converts an enzymatic activity into a physical signal. Only a few potentiometric immunosensors for environmental monitoring have been described in literature. For instance, Dzantiev et al. [23] reported the detection of $50 \mathrm{ppb}$ of the herbicide 2,4,5trichlorophenoxyacetic acid. The method is based on the competitive binding of free pesticide and pesticide-peroxidase conjugate with antibodies immobilized on a graphite electrode. In potentiometric biosensors are also included the immuno-FETs (field-effect transistors) and the LAPSs (Light-addressable potentiometric sensors). A LAPS device called Treshold ${ }^{\mathrm{TM}}$ from Molecular Devices Corp. (Palo Alto, USA) is on the market. This system is a silicon-based device for measuring potential changes.

An original potentiometric immunosensor has been described by Blackburn et al. (1990) [24] based on catalytic antibodies; this sensor combines the benefits of both immunosensors and catalytic sensors. The antibody is immobilized on a $\mathrm{pH}$ electrode and allows the detection of 0.7 ppm phenylacetate.

\section{Amperometric immunosensors}

Amperometric detection is based on the measurement at fixed potential of the current generated when electroactive species are either oxidized or reduced at the electrode. The current produced is directly related to the concentration of the electroactive species. There are only a few examples of amperometric immunosensors for environmental monitoring, they are all based on enzyme-labelled antibodies. As an example, Skládal and coll. [25] used a competitive device based on immobilized pesticide derivative (hapten) and peroxidase-labelled antibodies. Such a device allows the detection of $0.1 \mathrm{ppb}$ 2,4-dichlorophenoxyacetic acid (2,4-D).

\section{Other electrochemical immunosensors}

Conductimetric and impedimetric immunosensors have also been described for environmental monitoring. Conductimetry describes the dependence of the current generated ver sus a voltage while impedance refers to the dependence of the voltage versus the current. Sandberg et al. [26] (Ohmicron Corporation, Newtown, USA) developed a device allowing to measure $0.025 \mathrm{ppb}$ atrazine using an 
electroconductive polymer whose conductimetric properties change in the presence of $I_{3}^{-}$. This system involves a glucose oxidase(GOD)-labelled pesticide which competes with the pesticide present in the sample for the immobilized antibody. Hydrogen peroxide produced by GOD-reaction is reduced by lactoperoxidase with concomitant oxidation of $I^{-}$into $I_{3}^{-}$. Ohmicron Corp. company also reported a portable electrodebased immunoassay system called SmartSense ${ }^{\mathrm{TM}}$.

Due to their high specificity, immunosensors offer significant advantages as alternatives to conventional analytical methods. For determination of pesticide residues in drinking water, only antibody-based methods fit with the legislation of European Community, that set a maximum admissible concentration of $0.1 \mathrm{ppb}$ for individual pesticides and $0.5 \mathrm{ppb}$ for the sum total of all pesticides. However, immunoassay and immunosensor methods suffer from limitations; they are expensive and above all they allow the detection of one particular pesticide or a limited set of structurally similar cross-reacting residues.

More attention is now focused on the development of sensor methods that allow the detection of whole classes of pollutants and that can be used as general toxicity "index".

\section{Enzyme sensors}

Contrary to immunosensors, enzyme-based sensors can be considered as early-warning devices because they are sensitive to a relatively large spectrum of compounds. In the field of environmental monitoring, the major part of papers dealing with enzyme sensors are refering to the detection of pesticides and heavy metals.

The detection of pesticides is based, in some rare cases, on the catalytic transformation of the agrochemical by a selected enzyme, i.e. organophosphorus hydrolase for organophosphorus insecticides. Nevertheless, pesticides are toxic compounds that usually act by inhibiting one or several enzyme(s). The great majority of enzyme sensors for pesticides deal with the detection of organophosphorus and carbamate insecticides and are based on acetylcholinesterase (AChE) inhibition. In the case of organophosphorus insecticides which are irreversible inhibitors, one of the main requirements is to reactivate the inhibited enzyme in order to allow for continuous monitoring. The reactivation of the enzyme is performed by using a powerful nucleophilic reagent such as 2-PAM (pyridine-2-aldoxime methiodide) [27-29].

\section{Organophosphorus and carbamate insecticides}

Organophosphorus and carbamate insecticides represent a large percentage of the currently used pesticides (insecticides, fungicides, herbicides...). These pesticides have harmful consequences as they act as inhibitors of cholinesterases which are involved in neuronal transmission. The use of cholinesterase as a sensing element does not allow the selective detection of a particular pesticide, but provides an estimation of the total anticholinesterase activity present in a sample.

Electrochemical enzyme sensors are based either on potentiometric or amperometric detection; in this article we will focus on these two types of sensors (for a review, see [30]).

\section{Potentiometric enzyme sensors}

Potentiometric biosensors have been designed based on the measurement of $\mathrm{pH}$ change [27,31-36], electrode potential change $[37,38]$ or more sophisticated methods such as ionselective field-effect transistor (ISFET) [39-41] or lightaddressable potentiometric sensors (LAPS) [42-44].

The change in $\mathrm{pH}$ is induced by the formation of an organic acid during the hydrolysis of the choline ester by an appropriate esterase. The detection is then carried out using a simple $\mathrm{pH}$ electrode Using such a principle, Tran-Minh et al. [27] achieved the detection of $0.3 \mathrm{ppb}$ paraoxon, AChE being immobilized on a glass $\mathrm{pH}$ electrode by cross-linking with polyacrylamide. With the exception of this work, the detection limits reported are generally close to $3 \mathrm{ppb}$.

ISFET devices allow to achieve detection limits close to $0.2 \mathrm{ppm}$ paraoxon methyl [41] or dichlorvos [39,40]. LAPS devices seem to be more sensitive since $2.8 \mathrm{ppb}$ paraoxon can be detected [42-44].

Despite the potentiometric methods are fast and accurate, they show quite high detection limits. Furthermore, the detection of $\mathrm{H}^{+}$ions lacks sensitivity due to the consumption of protons by the buffer following proton liberation during the enzyme reaction.

\section{Amperometric enzyme sensors}

The amperometric method of detection is generally more sensitive and allows one to obtain a signal that is directly proportional to the analyte concentration. Depending on the cholinesterase substrate, different amperometric approaches have been described using mono- or bi-enzymatic systems based on the detection of thiocholine, $\mathrm{O}_{2}, \mathrm{H}_{2} \mathrm{O}_{2}$ or 4aminophenol.

With acetyl- or butyryl-choline as substrate, bienzyme electrodes based on the co-immobilization of a cholinesterase and ChOD have been reported, the detected species being oxygen or hydrogen peroxide [45-51]. Based on hydrogen peroxide oxidation, Mionetto et al. [48] reported the detection of $0.03 \mathrm{ppb}$ paraoxon using poly(vinyl alcohol) bearing styrylpyridinium groups (PVA-SbQ) as an immobilization matrix.

Using acetyl- or butyryl-thiocholine as substrate, the design of the sensor can be simplified as a monoenzymatic system can be used. The detection is based on the oxidation of the thiocholine produced by the enzyme reaction. In this way, the detection potential is lower than that used for the oxidation of hydrogen peroxide $(410 \mathrm{mV}$ instead of $650 \mathrm{mV}$ vs. $\mathrm{Ag} / \mathrm{AgCl}$ on platinum). Using $\mathrm{AChE}$ immobilized in a PVA-SbQ matrix, Marty et al. [29] succeeded in reaching a detection limit of $0.03 \mathrm{ppb}$ for paraoxon.

Using 4-aminophenyl acetate as a substrate, monoenzymatic devices have been also reported; in these cases oxidation of 4-aminophenol was performed at $0.25 \mathrm{~V}$ vs. SCE on a glassy carbon electrode [52-54]. With these electrodes, a detection limit of $1.1 \mathrm{ppb}$ paraoxon is possible. 
Finally, it is possible to enlarge the range of detectable compounds by using two different cholinesterases co-immobilized in the same biorecognition layer [55].

\section{Other pesticides}

Apart from the detection of insecticides with cholinesterasebased sensors, a few works have reported the detection of other pesticides such as dithiocarbamate fungiceides, sulfonylurea and imidazolinone herbicides and triazine berbicides.

\section{Dithiocarbamates fungicides}

Dithiocarbamate fungicides form the most important class of pesticides for the broad spectrum control of a variety of fungal diseases in crops. They are mainly composed of ethylenebis(dithiocarbamate) (maneb, zineb, mancozeb...) and dimethyldithiocarbamate compounds (ziram, ferbam...). Some biosensors for dithiocarbamates have been reported based on the inhibition of aldehyde dehydrogenase (AlDH) or tyrosinase. Marty and Noguer [56] developed an amperometric bienzymic sensor for the detection of ethylenebis(dithiocarbamate) by coupling AIDH with diaphorase, with detection based on hexacyanoferrate (II) oxidation. The optimization of enzyme loading and incubation time led to a detection limit as low as $1.5 \mathrm{ppb}$ maneb [57].

An alternative form of dithiocarbamate detection is to use tyrosinase as the target enzyme. Besombes et al. [58] used a polypyrrole membrane to detect, among other compounds, diethyldithiocarbamate. Since many dithiocarbamates are hydrophobic compounds, Wang et al. [59] described a sensor for diethyl-dithiocarbamates to be used in organic media. Another approach, based on reversed micelle systems, was reported by Pérez Pita et al. [60] in which a detection limit of $22.6 \mathrm{ppb}$ ziram was obtained.

\section{Triazine herbicides}

Triazine herbicides are photosynthesis inhibitors which are persistent and remain active in the environment for several years, causing continuous water pollution. The first enzyme sensor for the detection of these herbicides was that reported by McArdle and Persaud (1993) [61], based on tyrosinase inhibition. Using this principle, Mc Ardle and Persaud [61] and Besombes et al. [58] achieved a detection limit of around $1 \mathrm{ppm}$ atrazine. It must be stressed that tyrosinase has also been used for the detection of a wide range of pesticides and pollutants that can act as substrates or inhibitors $[58,62]$. This lack of specificity may be an advantage if the sensor is used as a warning system for general environmental pollution.

\section{Sulfonylurea and imidazolinone herbicides}

Sulfonylurea and imidazolinone herbicides (e.g. sulfometuron methyl, thifensulfuron methyl) are used for the control of broad-leaved weeds and grasses in cereal crops. Based on the fact that these herbicides are powerful inhibitors of acetolactate synthase (ALS), Seki et al. [63] reported the design of an amperometric biosensor enabling the detection of 0.4 ppm of sulfometuron methyl. In this system, the detection is based on the oxygenase side-activity of ALS.

\section{Whole cell sensors and organite-based sensors}

Biosensors using immobilized whole cell or organites have been described in literature based on the measurement of biochemical oxygen demand (BOD) or the quantitation of photosynthesis. Because of their broad specificity, whole cell biosensors have the potential to be used as early warning devices to monitor pollutants in waters.

\section{$B O D$ sensors}

BOD is the most important index of organic pollution in water. The conventional method to determine BOD is the "5days method" based on the measurement of oxygen consumption by microorganisms. This official method requires 5 days measurement. Since 1977, many papers have been published using various organisms: Trichosporum cutaneum [64,65] Clostridium butyricum [66], Hansenula anomala [67], Bacillus subtilis [68], Bacillus subtilis and Bacillus licheniformis $7 B$ [69]..., mixture of microorganisms [70] and thermophilic bacteria [71]. The best results were achieved with Trichosporum cutaneum. Using this strain, BOD sensor systems have already been commercialized by DKK Corporation (Japan), Nisshin Electric (Japan), Medingen (Germany). All these sensors are based on the immobilization of microorganisms on a Clark oxygen electrode. Depending on the systems, BOD measurements can be realized within minutes. BOD sensors based on the use of other strains have been developed by Dr. Lange Company (Germany) (Rhodococcus erythropolis and Issatchenkia ori entalis) and Autoceam (Germany).

\section{Photosynthesis monitoring sensors}

Approximately $30 \%$ of commercial herbicides act on photosynthetic systems. The main part are inhibitors of photosynthetic electron transport (PET), some inhibit phosphorylation, others inhibit both processes [72]. Herbicides such as atrazine (s-triazine), isoproturon (phenylurea) block electron flow in PSII, others like propanil (acylanilide) or bromoxynil (halogenated benzonitrile) also act on phosphorylation. The detection of these herbicides by sensors has been described using various biological receptors such as cyanobacteria [73], the microalga Chlorella vulgaris [74], chloroplast [75] or thylakoid membranes [76], Synechoccus sp. prokaryotic cells [73], isolated reaction center from the bacterium Rhodobacter sphaeroides [77]. The inhibitory effect of herbicides can be assessed by using a modified grating coupler [77], an oxygen electrode [74], an amperometric detection of an electron mediator such as ferrycianide or $p$-benzoquinone [73]. Contrary to eucaryotic algae or chloroplasts from higher plants which can be coupled to oxygen measurement, cyanobacteria require a mediator such as ferricyanide for amperometric detection of the photosynthetic reaction [78].

Generally, photosynthesis monitoring sensors suffer from a lack of sensitivity, especially when compared to immunosensors. For instance, the limit of detection for atrazine varies from $10 \mathrm{ppb}$ to $650 \mathrm{ppb}$ using cyanobacteria [73,78], unicellular algae [74], thylakoids [76], and reaction centers [77]; whereas using immunosensors, concentrations as low as $0.03 \mathrm{ppb}$ can be detected [13]. 


\section{Conclusion}

The relatively low cost of biosensors compared to classical methods such as spectrophotometry and chromatography strongly suggests that there could be a significant market in the field of environmental monitoring. Moreover, the use of biosensors seems promising since they are also fast and portable analytical methods which allow on-line measurements.

In the field of pesticide analysis, immunosensors allow to achieve very low detection limits when compared to other analytical methods. The main criticism of immunochemical methods is that they are too specific. The successful application of immunosensors to environmental analysis will depend on the commercial availability of the appropriate immunochemicals.

Contrary to immunosensors, enzyme sensors seem better addressed to class-specific devices, allowing the detection of broad families of pollutants and in some cases their metabolites, so that they can be used as alarm systems. The main problems of enzyme sensors remain commercial availability and stability of enzymes. The number of natural enzymes that can be isolated and directly used is very limited. Much studies are devoted to the improvement of enzyme stability in biosensors. Investigations now focus on the isolation from natural or genetically engineered thermophilic microorganisms of enzymes showing enhanced stability at high temperatures. The development of artificial enzymes bearing functional moities that mimic natural enzyme activity, named "synzymes" is also particularly promising.

Biosensors will undoubtedly play an important role in future environmental monitoring practices. Nevertheless, some critical parameters such as stability, accuracy and reliability still have to be improved in order to transfer biosensor technology to industrial and domestic applications.

\section{References}

1. Coulet, P. R. In: Biosensor principles and applications, Blum, L. J.; Coulet, P. R. Eds., Marcel Dekker, Inc., New York, 1991; pp 1-6.

2. Marco, M. -P.; Barceló, D. Meas. Sci. Technol. 1996, 7, 15471562.

3. Berson, S. A.; Yalow, R. S. Ann. N. Y. Acad. Sci. 1959, 82, 338-344.

4. Engvall, E.; Perlmann, P. Immunochemistry 1971, 8, 871-874.

5. Van Weemen, B. K.; Schuurs, H. H. W .M. FEBBS Lett. 1971, $15,232-236$.

6. Hammock, B. D.; Mumma, R. O. In: Pesticide Analytical Methodology, Harvey, J.; Zweig, G.; Eds., ACS Symp. Series, Washington, DC, 1980; Vol. 136, pp 321-352.

7. Nelson, J. O.; Karu, A. E.; Wong; R. B. In: Immunoanalysis of Agrochemicals, Emerging Technologies, ACS Symp. Series, ACS, Washington DC, 1995, Vol. 586.

8. Marco, M. P.; Gee, S.; Hammock, B. D. Trends Anal. Chem. 1995, 14, 341-350.

9. Sherry, J. P. Crit. Rev. Anal. Chem. 1992, 23(4), 217-300.

10. Meulenberg, E. P.; Mulder, W. H.; Stoks, P. G. Environ. Sci. Technol. 1995, 29(3), 553-561.

11. Sadik, O. A.; Van Emon, J. M. Biosensors Bioelectronics 1996, 11(8), i-xi.
12. Ngeh-Ngwainbi, J.; Foley, P. H.; Kuan, S. S.; Guilbault, G. G. J. Am. Chem. Soc. 1986, 108, 5444-5447.

13. Guilbault, G. G.; Hock, B.; Schmid, R. Biosensors Bioelectronics 1992, 7, 411-419.

14. Steegborn, C.; Skladal, P. Biosensors Bioelectronics 1997, 12, 19-27.

15. Anis, N. A.; Wright, J.; Rogers, K. R.; Thompson, R. G.; Valdes, J. J.; Eldefrawi, M. E. Anal. Lett. 1992, 25, 627-635.

16. Anis, N. A.; Eldefrawi, M. E.; Wong, R. B. J. Agric. Food Chem. 1993, 41, 843-848.

17. Bier, F. F.; Schmid, R. D. Biosensors Bioelectronics 1994, 9 , 125-130.

18. Dzantiev, B. B.; Zherdev, A. V.; Yulaev, M. F.; Sitdikov, R. A.; Dmitrieva, N. M.; Moreva, I. Y. Biosensors Bioelectronics 1996, 11, 179-185.

19. Ghindilis, A. L.; Krishnan, R.; Atanasov, P.; Wilkins, E. Biosensors Bioelectronics 1997, 12, 415-423.

20. Minunni, M.; Mascini, M. Anal. Lett. 1993, 26, 1441-1460.

21. Wong, R. B.; Anis, N.; Eldefrawi, M. E. Anal. Chim. Acta 1993, 279, 141-147.

22. Zhao, C. Q.; Anis, N. A.; Rogers, K. R.; Kline, R. H.; Wright, J.; Eldefrawi, A.T.; Eldefrawi, M.E. J. Agric. Food Chem. 1995, 43, 2308-2315.

23. Dzantiev, B. B.; Zherdev, A. V.; Yulaev, M. F.; Sitdikov, R. A.; Dmitrieva, N. M.; Moreva, I. Y. Biosensors Bioelectronics 1996, 11, 179-185.

24. Blackburn, G. F.; Talley, D. B.; Booth, P. M.; Durfor, C. N.; Martin, M. T.; Napper, A. D.; Rees, A. R. Anal. Chem. 1990, 62, 2211-2216.

25. Kalab, T.; Skladal, P. Anal. Chim. Acta 1995, 304, 361-368.

26. Sandberg, R. G.; Van Houten, L. J.; Schwartz, J. L.; Bigliano, R. P.; Dallas, S. M.; Silvia, J. C.; Cabelli, M. A.; Narayanswamy, V. ACS Symp. Ser. 1992, 511, 81-88.

27. Tran-Minh, C.; Pandey, P. C.; Kumaran, S. Biosensors Bioelectronics 1990, 5, 461-471.

28. Mionetto, N.; Marty, J. -L.; Karube, I. Biosensors Bioelectronics 1994, 9, 463-470.

29. Marty, J. -L.; Mionetto, N.; Lacorte, S.; Barceló, D. Anal. Chim. Acta 1995, 311, 265-271.

30. Trojanowicz, M.; Hitchman, M. L. TrAC 1996, 15, 38-45.

31. Durand, P.; Thomas, D. J. Environ. Pathol. Toxicol. Oncol. 1984, 5, 51-57.

32. El Yamani, H.; Tran-Minh, C.; Abdul, M.; Dupont, M. J. Franç. d'Hydrobiol. 1987, 18, 67-75.

33. El Yamani, H.; Tran-Minh, C.; Abdul, M. A.; Chavanne, D. Sensors Actuators 1988, 15, 193-198.

34. Tran-Minh, C. Anal. Proc. 1993, 30, 73-74.

35. Kumaran, S.; Morita, M. Talanta 1995, 42(4), 649-655.

36. Budnikov, H. C.; Evtugyn, G. A. Electroanal. 1996, 8, 817820.

37. Ghindilis, A. L.; Morzunova, T. G.; Barmin, A. V.; Kurochkin, I. N. Biosensors Bioelectronics 1996, 11(9), 873-880.

38. Ivnitskii, D. M.; Rishpon, J. Biosensors Bioelectronics 1994, 9, 569-576.

39. Dumschat, C.; Müller, H.; Stein, K.; Schwedt, G. Anal. Chim. Acta 1991, 252, 7-9.

40. Vlasov, Y.; Bratov, A.; Levichev, S.; Tarantov, Y. Sensors Actuators B 1991, 4, 283-286.

41. Nyamsi Hendji, A. M.; Jaffrezic-Renault, N.; Martelet, C.; Clechet, P.; Shul'ga, A. A.; Strikha, V. I.; Netchiporuk, L. I.; Soldatkin,A. P.; Wlodarski, W. B. Anal. Chim. Acta 1993, 281, 3-11.

42. Rogers, K.R.; Foley, M.; Alter, S.; Koga, P.; Eldefrawi, M. Anal. Lett. 1991, 24, 191-198. 
43. Fernando, J. C.; Rogers, K. R.; Anis, N. A.; Valdes, J. J.; Thompson, R. G.; Eldefrawi, A. T.; Eldefrawi, M. E. J. Agric. Food Chem. 1993, 41, 511-516.

44. Dehlawi, M. S.; Eldefrawi, A. T.; Eldefrawi, M. E.; Anis, N. A.; Valdes, J. J. J. Biochem. Toxicol. 1994, 9(5), 261-268.

45. Bernabei, M.; Cremisini, C.; Mascini, M.; Palleschi, G. Anal. Lett. 1991, 24, 1317-1331.

46. Wollenberger, U.; Setz, K.; Scheller, W.; Löffler, U.; Göpel, W.; Gruss, R. Sensors Actuators B 1991, 4, 257-260.

47. Marty, J. -L.; Sode, K.; Karube, I. Electroanal. 1992, 4, 249252.

48. Mionetto, N.; Rouillon, R.; Marty, J. -L. Z. Wasser-AbwasserForsch. 1992, 25, 171-174.

49. Cremisini, C.; Di Sario, S.; Mela, J.; Pilloton, R.; Palleschi, G. Anal. Chim. Acta 1995, 311, 273-280.

50. Cagnini, A.; Palchetti, I.; Mascini, M.; Turner, A. P. F. Mikrochim. Acta 1995, 121, 155-166.

51. Cagnini, A.; Palchetti, I.; Lionti, I.; Mascini, M.; Turner, A. P. F. Sensors Actuators B 1995, 24-25, 85-89.

52. La Rosa, C.; Pariente, F.; Hernandez, L.; Lorenzo, E. Anal. Chim. Acta 1994, 295, 273-282.

53. La Rosa, C.; Pariente, F.; Hernandez, L.; Lorenzo, E. Anal. Chim. Acta 1995, 308, 129-136.

54. Pariente, F.; La Rosa, C.; Galan, F.; Hernandez, L.; Lorenzo, E. Biosensors Bioelectronics 1996, 11, 1115-1128.

55. Sklàdal, P.; Pavlìk, M.; Fiala, M. Anal. Lett. 1994, 27, 29-40.

56. Marty, J. -L.; Noguer, T. Analusis 1993, 21, 231-233.

57. Noguer, T.; Marty, J. -L. Anal. Chim. Acta 1997, 347, 63-70.

58. Besombes, J. -L.; Cosnier, S.; Labbé, P.; Reverdy, G. Anal. Chim. Acta 1995, 311, 255-263.

59. Wang, J.; Dempsey, E.; Eremenko, A.; Smyth, M. R. Anal. Chim. Acta 1993, 279, 203-208.

60. Pérez Pita, M. T.; Reviejo, A. J.; Manuel de Villena, F. J.; Pingarron, J. M. Anal. Chim. Acta 1997, 340, 89-97.

61. McArdle, F. A.; Persaud, K. C. Analyst 1993, 118, 419-423.
62. Besombes, J. -L.; Cosnier, S.; Labbé, P.; Reverdy, G. Anal. Lett. 1995, 28(3), 405-424.

63. Seki, A.; Ortéga, F.; Marty, J. -L. Anal. Lett. 1996, 29(8), 1259-1271.

64. Riedel, K.; Lange, K. P.; Stein, H. J.; Kuhn, M.; Ott, P.; Scheller, F. Water Research 1990, 24(7), 883-887.

65. Marty, J. -L.; Olive, D.; Asano, Y. Environ. Technol. 1996, 18, 333-337.

66. Karube, I.; Matsunaga, T.; Suzuki, S. J. Solid-Phase Biochem. 1977, 2, 97-104.

67. Kulys, J.; Kadziauskiene, K. Biotechnol. Bioeng. 1980, 22, 221-226.

68. Riedel, K.; Renneberg, R.; Kuhn, M.; Scheller, F. Applied Microb. Biotechnol. 1988, 28, 316-318.

69. Tan, T. C.; Li, F.; Neoh, K. G. Sensors Actuators B 1993, 10, 137-142.

70. Stand, S. E.; Carlson, D. A. JWPCF 1984, 56(5), 464-467.

71. Karube, I.; Yokoyama, K.; Sode, K.; Tamiya, E. Anal. Lett. 1989, 22(4), 791-801.

72. Trebst, A.; Draber, W. In: Advances in Pesticide Science, Geissbuehler, H. et al. Eds., Pergamon, New York, 1978, Part 2; pp 222-234.

73. Rawson, D. M.; Willmer, A. J.; Turner, A. P. F. Biosensors 1989, 4, 299-311.

74. Pandar, P.; Rawson, D. M. Environ. Toxicol. Water Qual.: An Int. J. 1993, 8, 323-333.

75. Rouillon, R.; Tocabens, M.; Marty, J. -L. Anal. Lett. 1994, 27, 2239-2248.

76. Rouillon, R.; Sole, M.; Carpentier, R.; Marty, J. -L. Sensors Actuators B 1995, 26-27, 477-479.

77. Jockers, R.; Bier, F. F.; Schmid, R. D. Anal. Chim. Acta 1993, 280, 53-59.

78. Rawson, D. M.; Willner, A. J.; Cardosi, M. Toxicity Assessment: An Int. Quart. 1987, 2, 325-340. 